\title{
Study on the Impact of Agricultural Technology Progress on Grain Production and Farmers' Income
}

\author{
Bing Lin ${ }^{1 *}$, Cengceng $\mathrm{Wu}^{2}$ \\ ${ }^{1}$ International Economics and Trade Department, School of Economics, Shandong University of Technology, Zibo, China \\ ${ }^{2}$ School of Economics, Shandong University of Technology, Zibo, China \\ Email: ${ }^{\star} 110235359 @ q q . c o m$
}

How to cite this paper: Lin, B. and $\mathrm{Wu}$, C.C. (2021) Study on the Impact of Agricultural Technology Progress on Grain Production and Farmers' Income. Open Access Library Journal, 8: e7991.

https://doi.org/10.4236/oalib.1107991

Received: September 23, 2021

Accepted: October 31, 2021

Published: November 3, 2021

Copyright $\odot 2021$ by author(s) and Open Access Library Inc.

This work is licensed under the Creative

Commons Attribution International

License (CC BY 4.0).

http://creativecommons.org/licenses/by/4.0/

(c) (i) Open Access

\begin{abstract}
Agricultural technological progress plays an important role in a country's food security and farmers' income. This paper analyzes the current situation of agricultural technology progress, grain production and farmers' income in China. Secondly, the problems and causes about grain production and farmers' income are researched. At last, policies and measures are put forward on how to use agricultural technological progress to promote grain output and increase farmers' income.
\end{abstract}

\section{Subject Areas}

Development Economics

\section{Keywords}

Agricultural Technology Progress, Grain Production, Farmers' Income

\section{Introduction}

China is in a critical period of transforming the mode of agricultural development, increasing farmers' income and revitalizing the rural economy. But there are still important problems to be solved. As we all know, China has a large population, and under the effect of a large number of rural labor has moved to cities and the decrease in cultivated area, and the relationship between grain supply and demand tends to be strained, so people are worried about food security. At the same time, the slow growth of farmers' income has become an important factor restricting the further development of China's rural economy. Therefore, ensuring food security and increasing farmers' incomes is a challenge for agri- 
culture. It is also an important component of implementing the rural vitalization strategy and agricultural modernization. Is agricultural technological progress an important force in increasing grain production and farmers' income? What needs to be done to improve the policies and measures to increase grain production and farmers' income? This paper analyzes the current situation of agricultural technological progress, grain production and farmers' income using the data from China Statistical Yearbook and China Rural Statistical Yearbook. We statistically study the existing problems by figures and charts, then put forward policies and measures to promote grain production and farmers' income through agricultural technological progress.

\section{Materials}

\subsection{About Agricultural Technology Progress and Grain Production}

In the early stage, scholars focused on the relationship between agricultural total factor productivity (TFP) and grain output. They analyzed the influencing factors, which improved agricultural TFP and increased grain production through agricultural technology progress. Garnett et al. (2013) [1] pointed out that the primary way to reduce poverty and achieve food security is to improve agricultural TFP. Some scholars also put forward the opinions that improving agricultural technology can not only improve grain output, but also develop reserve grain resources. With the further deepening of research, scholars have shifted focuses to the spatial spillover effect of agricultural technological progress in recent years. The inter-regional operation of agricultural machinery can not only produce specialized division of labor through scale effect, but also improve labor efficiency and increase grain yield through spillover effect of technology.

\subsection{About Agricultural Technology Progress and Farmer's Income}

The effects of technology progress on farmers' income have two aspects. One is a direct effect. Agricultural technology progress formed new competitive advantages of agricultural products, which promoted farmers' income by different channels, such as saving production costs, increasing product types, improving product quality and efficiency, and improving production modes. Li Zhongpeng (2006) [2] pointed out that the new agricultural business with high demand elasticity generated by agricultural technological progress have promoted the increasing of farmers' income. The second is an indirect effect. Technological progress can improve agricultural production efficiency and promote the transfer of a large number of rural labor from the primary industry to the secondary and tertiary industries. These transformations can make farmers increase their income indirectly. Yang Yiwu and Lin Wanlong (2016) [3] tested the increasing effect of technology progress on farmers' income by using dynamic GMM model estimation and found a significant positive effect on farmers' wage income and per ca- 
pita net income. Li Ping et al. (2012) [4] further pointed out that agricultural technological progress had a significant positive impact on non-agricultural employment of rural labor force. Wang Aimin and Li Zilian (2012) [5] also drew a similar conclusion that technological progress had a significant indirect effect on farmers' income. Some pointed out that agricultural technological progress could increase grain production by improving grain yield and labor efficiency [6] [7].

\section{Discussion}

\subsection{Discussion on Agricultural Technological Progress in China}

As shown in Figure 1, the total power of agricultural machinery in China reached 52.574 million $\mathrm{kw}$ in 2000. Then it grew steadily to 111,728 kilowatts in 2015 and only was a decline in 2016, which was caused by the reduction of small agricultural machinery and tools. In 2019, the total power of China's agricultural machinery was about 102.758 million $\mathrm{kw}$, an increase of $0.2 \%$ compared to 2018 . Due to the loss of agricultural labor force in China, mechanization of agricultural production has become a general trend. It can be concluded that China's agricultural technology has made continuous progress and agricultural modernization has reached a new stage.

\subsection{Discussion on Current Situation of Grain Production in China}

During the 13th Five-Year Plan period (2016-2020), major progress was made in modern agriculture and a solid start was made in rural revitalization. The annual grain output continuously reached above 1.3 trillion gold. The farmers' income was more than twice as much as 2010. As shown in Figure 2, the change trend of total grain output and sown area is very similar, which indicates that variation trend of total grain output is closely related to that of sown area. It can be said that the decrease of crop sown area restricts the increase of total grain production to a certain extent. Therefore, it is an inevitable choice to increase grain production by improving grain unit area production level.

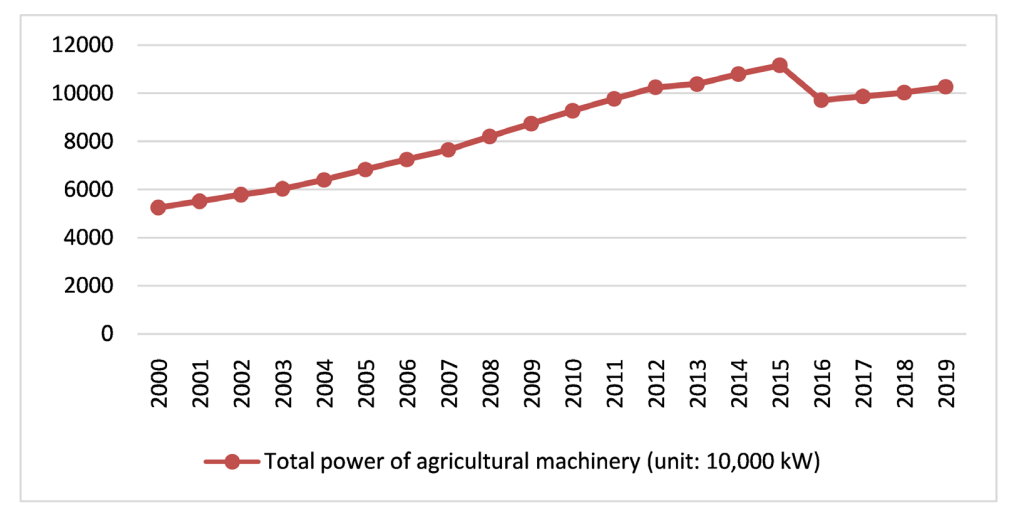

Figure 1. Bar chart of total power changes of agricultural machinery (20002019). Data source: Collated according to China Rural Statistical Yearbook. 


\subsection{Discussion on Farmers' Income Status in China}

As shown in Figure 3, the per capita disposable income of farmers increased seven-fold from 2000 to 2019, per capita disposable income increased from 2282.2 Yuan to $16,020.7$ Yuan.

As shown in Figure 4, the growth rate of per capita disposable income was lower than that of GDP from 2000 to 2019, and per capita disposable income grew slowly, percapita disposable income reached 16,020.7 Yuan in 2019, an increase of 9.6 percent compared to 2018, but slower than the 11.2 percent in 2014 and even lower than the 12.4 percent in 2013.

As shown in Figure 5, over the past 20 years, the ratio of net operating income to per capita disposable income declined by 26.6 percent, on the contrary, the ratio of wage income to per capita disposable income increased by 10.3 percent. The ratio of transfer net income kept increasing, while the ratio of property net income remained almost unchanged.

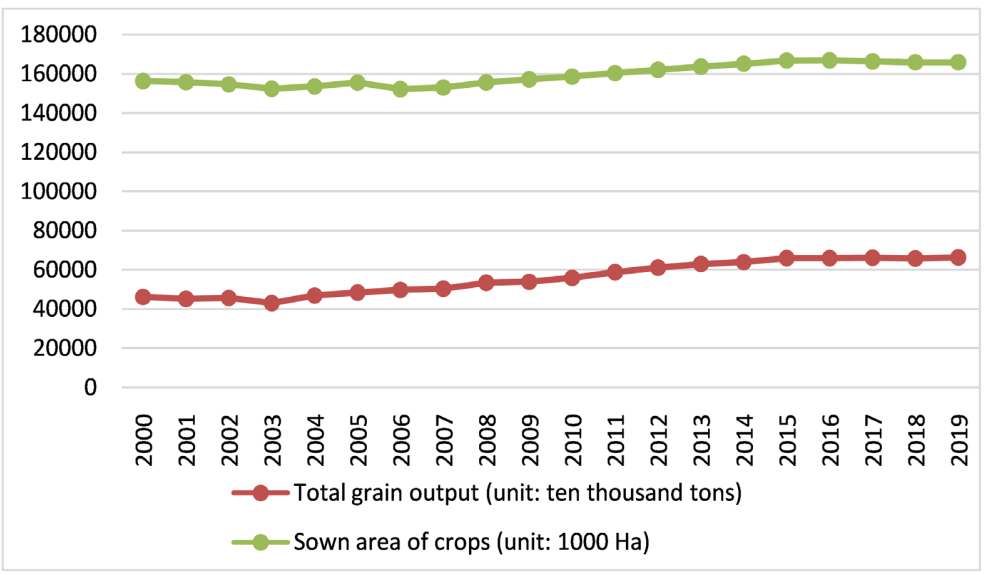

Figure 2. Line chart of changes in total grain output and sown area (20002019). Data source: Collated and calculated according to China Rural Statistical Yearbook.

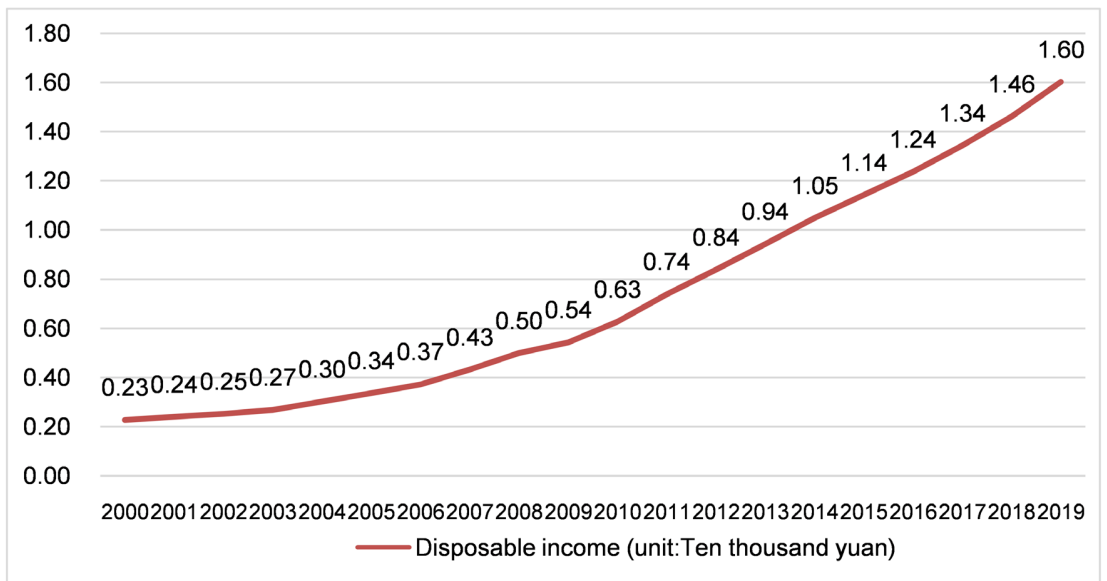

Figure 3. Growth curve of per capita disposable income (2000-2019). Data source: Collated and calculated according to China Rural Statistical Yearbook. 


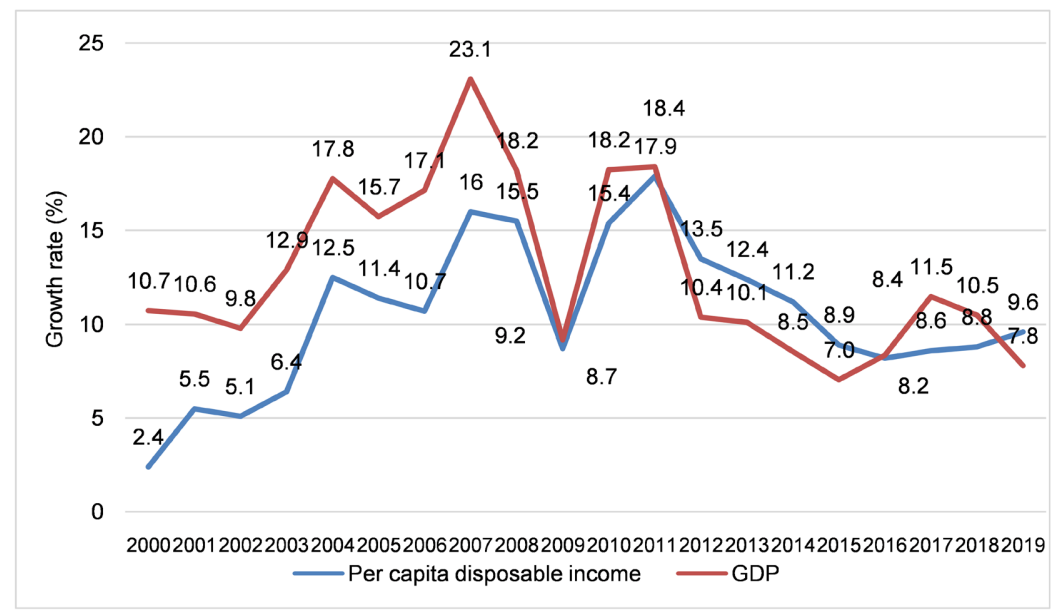

Figure 4. Per capita disposable income and GDP growth rate of rural residents (20002019). Data source: Collated and calculated according to China Statistical Yearbook and China Rural Statistical Yearbook.

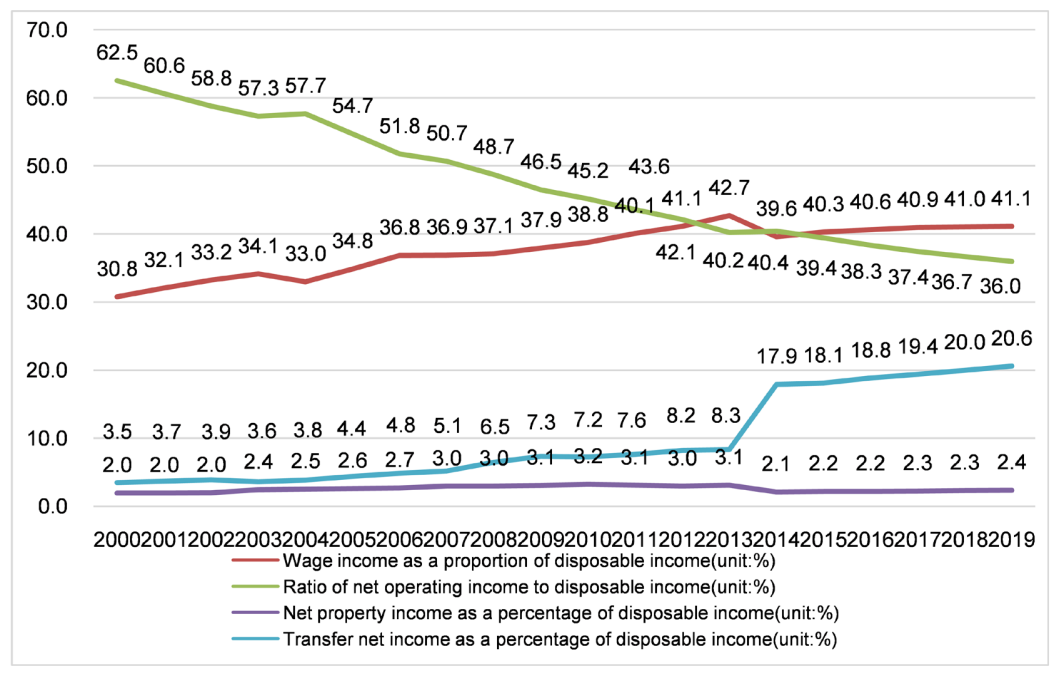

Figure 5. Line chart of changes in the per capita disposable income of rural residents (2000-2019). Data source: Collated and calculated according to China Rural Statistical Yearbook.

As shown in Figure 6, in the composition of agricultural net income from 2000 to 2019 , the proportion of primary industry decreased by 11.7 percent, that of secondary industry increased by 0.2 percent, and that of tertiary industry increased by 11.5 percent.

As can be seen from Figure 7, the proportion of the primary industry in rural employment decreased by 15.2 percent, and the number of agricultural workers became less and less.

\section{Results}

\subsection{China Has Made Great Progress in Agricultural Technology}

Agricultural technological progress can provide advanced agricultural technology and equipment, which constantly improve the productivity of labor, the 


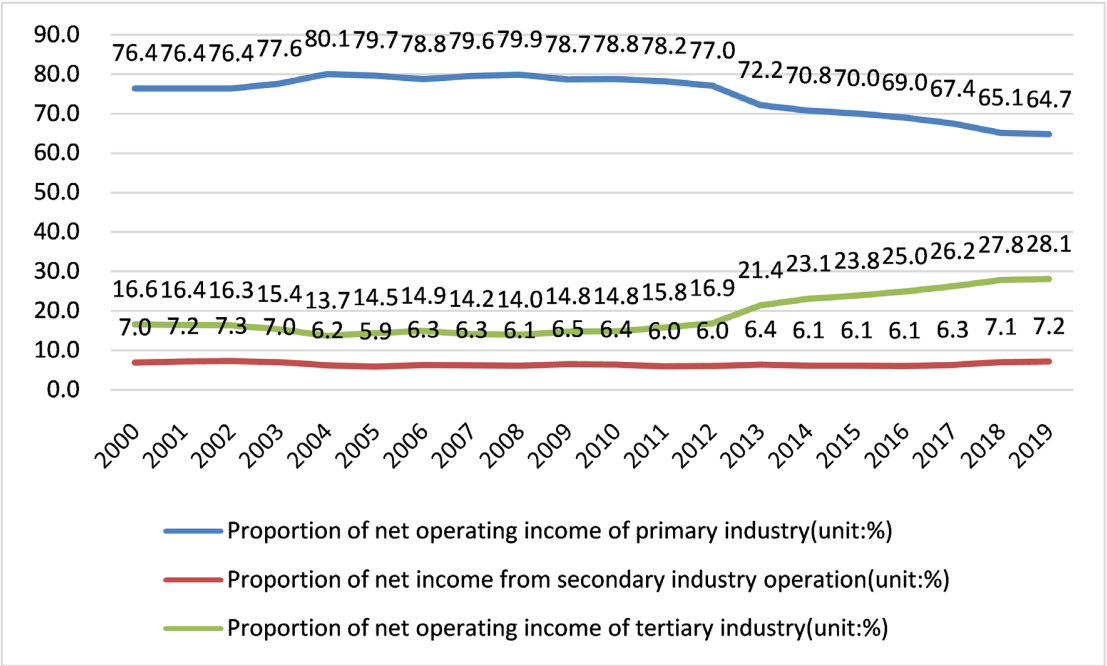

Figure 6. Change curve of components of net operating income (2000-2019). Data source: Collated and calculated according to China Rural Statistical Yearbook.

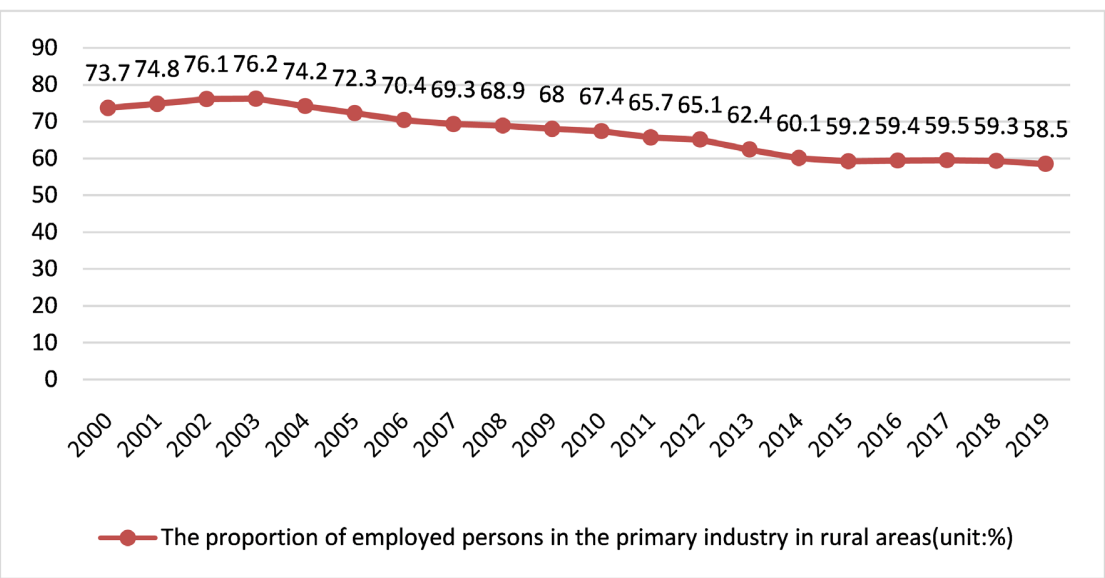

Figure 7. Change curve of the proportion of primary industry in rural employment (20002019. Data source: Collated and calculated according to China Rural Statistical Yearbook.

productivity of land and the quality of agricultural products. It also make full use of the resources to improve the agricultural economic benefits, and promote the economic development of the whole rural area.

\subsection{The Motivation of Grain Production Is Not Enough Because of Different Agricultural Problems}

The problems of aging of China's population, the "hollowing out" of rural areas and the deterioration of rural ecological environment limit the input factors of grain production. The decrease of crop sown area restricts the increase of total grain production. The motivation of grain production is not enough.

\subsection{The Structure of Farmers' Income Changes Greatly}

Although the per capita disposable income of Chinese farmers has improved greatly since 2000, but the growth rate is still low. In addition, the structure of 
farmers' income has also changed greatly, and the proportion of net income from agricultural operations in farmers' disposable income is constantly decreasing. Among the various components of net income from agricultural operations structure, the proportion of primary industry is getting smaller, while the proportion of secondary and tertiary industries is getting larger.

\subsection{The Proportion of Primary Industry in Rural Employment Has Been Declining}

The proportion of the primary industry in rural employment continues to decline, and the number of agricultural workers is getting smaller and smaller, or the number of full-time workers in agriculture-related industries is getting smaller and smaller. However, the total crop output has never declined in recent years, which is largely dependent on the progress of agricultural technology.

\section{Strategy}

\subsection{To Promote the Agricultural Mechanization}

It is necessary to vigorously promote agricultural mechanization, especially in the western regions in China where labor productivity is low. The development of agricultural mechanization can not only solve the problem of the insufficiency of the agricultural labor force in the region and ensure the safety of grain output, but also release a large number of surplus labor force in western region, which can promote employment transferring, and increase the wage income of farmers. The industrial chain construction of agricultural extension agencies should be guided by government through financial policy support, ensuring that relevant funds can be timely and effectively applied to support agricultural mechanization projects.

\subsection{To Increase the Support for Agricultural Research and Adjust Direction of Support}

The governments actively should carry out cooperation with higher education institutions and related agricultural research institutions, and form an organic ecosystem by connecting scientific research, technology, funds and projects. Government should also create a better environment for a virtuous cycle between agricultural technology and farmers' income.

\subsection{To Pay Attention to the Improvement of the Quality Level for the Science and Technology Education in Rural Areas}

On the one hand, the government should increase the investment and the hardware facilities for the science and technology education in rural areas; on the other hand, the government should establish an exchange mechanism for urban and rural teachers, and at the same time increase the level of treatment and subsidies for rural teachers, so as to attract and retain talents and inject fresh force into the science and technology education in rural areas. The government should 
set up training courses of agricultural science and technology with regional characteristics according to the characteristics of agricultural production in different regions, and transforming surplus rural labor into industrial workers, which benefits to play the full role of agricultural technological progress in improving farmers' wage income.

\subsection{To Improve the Rural Land Transfer Mechanism and the Large-Scale Development of Agriculture}

More subsidies and preferential policies should be given to large-scale farmers in agricultural machinery purchase and financial support. The large-scale development of agriculture is not only conducive to the R \& D and use of agricultural technology, but also change the traditional agricultural development mode, significantly improve the efficiency of agricultural production and operation, improve grain output and increase the income level of farmers.

\section{Conclusion}

This paper analyzes the status quo of China's agricultural technological progress, grain production and farmers' income in China. It discusses the existing problems and causes, and concludes that the progress of agricultural technology has a great impact on the increase of grain output and the increase of farmers' income. So, conclusions have been drawn: 1) China's agricultural technology has made great progress and the level of mechanization of agricultural production has improved. 2) The motivation of grain production is not enough because of different agricultural problems. 3) The structure of farmers' income changes greatly. 4) The proportion of primary industry in rural employment has been declining. Strategies have been put forward to promote food production and farmers' income through technological progress in agriculture. In the future, we would further clarify the mechanism and function of agricultural scientific and technological progress to increase grain production and farmers' income and adjust the input direction of agricultural scientific and technological progress.

\section{Conflicts of Interest}

The authors declare no conflicts of interest.

\section{References}

[1] Garnett, T., Appleby, M.C., Balmford, A., et al. (2013) Sustainable Intensification Agriculture: Premises and Policies. Science, 7, 33-34.

[2] Li, Z.P. (2006) Technological Progress and Farmers' Income Increase. Rural Economy, 11, 57-59.

[3] Yang, Y.W. and Lin, W.L. (2016) Effects of Agricultural Technological Progress on Income Growth: A Test Based on Provincial Panel Data in China. Economic Science, 5, 46-56.

[4] Li, P., Zhao, K. and Zhang, J.B. (2012) Analysis on the Relationship between Science and Technology Input and Non-Agricultural Employment. Studies in Science of Sci- 
ence, 30, $81-87$

[5] Wang, A.M. and Li, Z.L. (2012) Research on the Effect of Agricultural Technology Progress on Farmers' Income. Economic Longitude, 31, 31-36.

[6] Huang, X., Wang, Z. and Ren, Z. (2021) Research on the Influence of Urbanization Structure on Farmers' Income Increase-Based on the Perspective of Income Structure. Open Journal of Social Sciences, 9, 540-552. https://doi.org/10.4236/jss.2021.95029

[7] Sudswang, A., Somjai, S. and Toopgrajank, S. (2018) Management and Agricultural Technology Affecting to Longan Security in Thailand. World Journal of Engineering and Technology, 6, 738-751. https://doi.org/10.4236/wjet.2018.64048 